267

\section{SOLUBLE GUANYLATE CYCLASE STIMULATION REDUCES INFARCT SIZE AND POST-INFARCT HEART FAILURE IN MOUSE HEARTS}

C Methner, ${ }^{1}$ T Krieg, ${ }^{1}$ A Vujic, ${ }^{1}$ G Buonincontri, ${ }^{1}$ A Carpenter, ${ }^{1}$ A Kretschmer, ${ }^{2}$ Johannes-Peter Stasch ${ }^{2}{ }^{1}$ University of Cambridge, ${ }^{2}$ Bayer Healthcare

doi:10.1136/heartjnl-2013-304019.267

Introduction Activation of the nitric oxide-protein kinase $G$ pathway confers protection against acute ischemia/reperfusion injury, but more chronic effects in reducing post-myocardial infarction (MI) heart failure are less defined. The aim of this study was to determine whether riociguat, a selective soluble guanylate cyclase (sGC) stimulator, not only reduces infarct size but also protects against the development of post-MI heart failure.
Methods Mice were subjected to $30 \mathrm{~min}$ ischemia via ligation of the left main coronary artery to induce MI and either placebo or riociguat $(1.2 \mu \mathrm{mol} / \mathrm{l})$ were given as a bolus $5 \mathrm{~min}$ before and $5 \mathrm{~min}$ after onset of reperfusion. After 24 hours, both, late gadolinium-enhanced magnetic resonance imaging (LGE-MRI) and 18F-FDG-positron emission tomography (PET) were performed to determine infarct size and cardiac function. Furthermore riociguats effect on blood pressure was tested by either the non-invasive tail cuff assessment or the LV catheterization via the right carotid artery.

Results In the riociguat-treated mice, the resulting infarct size was smaller $(21.8 \% \pm 1.7 \%$ vs. $8.5 \pm 2.5 \%$ of total LV mass, $p=0.005)$, and LV systolic function was better preserved $(44.2 \% \pm 3.1 \%$ vs. $60.1 \%$ $\pm 3.4 \%, p=0.005$ ) compared to control animals. After 28 days, echocardiography showed markedly preserved LV systolic function $(48.2 \% \pm 2.2$ vs. $63.5 \% \pm 3.2 \%, p=0.004)$ in the group treated with riociguat compared to control. Riociguat showed no significant effect on blood pressure.

Conclusion Taken together, mice treated acutely at the onset of reperfusion with the sGC stimulator riociguat have smaller infarct size, better preserved LV systolic function and develop less adverse LV remodeling. These findings suggest that sGC stimulation after an acute MI may be a powerful therapeutic treatment strategy for post-MI heart failure. 